\title{
A flexible arrangement for the study of moles in captivity
}

\author{
Anna BORRONI, Anna LOY and Ernesto CAPANNA
}

\begin{abstract}
Borroni A., Loy A. and Capanna E. 1999. A flexible arrangement for the study of moles in captivity. Acta Theriologica 44: 207-214.

A new arrangement for keeping moles in captivity was designed by combining newly conceived units and different types of structures previously described by other authors. The structure is especially devoted to long term studies, such as those on activity patterns and reproductive and social behaviours. A simple and economic system for automatic recording of activity rhythms in moles is also presented and discussed.
\end{abstract}

Dipartimento di Biologia Animale e dell'Uomo, Università degli Studi di Roma 'La Sapienza', Via Borelli 50, 00161 Rome, Italy

Key words: moles, captivity, automatic recording

\section{Introduction}

Moles are strictly fossorial insectivores highly adapted to the underground life, which show unique physiological, morphological and behavioural adaptations. The special conditions under which moles live impose several constraints to the investigation of activity rhythms and behaviour of these animals in the field. Therefore data from captive animals can highly improve our knowledge of the biology of these fossorial mammals. Here we describe a new arrangement designed for the study of both behaviour and activity rhythms of moles in captivity. We combined the characteristics of keeping arrangements designed by Skoczen (1961), Rudge (1966), Witte (1981) and Redfern and Mitchell (1987), and added some new structures. We also evaluated the importance of earth and of different parts of the arrangement that the moles came in contact with. A simple and economic system for the automatic recording of activity rhythms in moles is also presented. Since the structure was tested during an experimental study on the seasonal activity patterns of Talpa romana (A. Loy, S. Martullo, A. Borroni, E. Capanna and M. P. Gerkema, in prep.), each animal was kept in captivity for a maximum of about 3 months, and then released to allow the recording of newly captured moles.

\section{Material and methods}

\section{Accommodation unit}

Field studies have revealed that moles are solitary and territorial animals, each individual occupying almost exclusive ranges (Gorman and Stone 1990, Loy et al. 1994). Therefore each cage is 
designed to house one animal at a time, leaving the possibility of connecting two or more cages if needed. Every accommodation unit consists of a nest box, a water box, a food box, a vertical box filled with soil, and a net run (Fig. 1). The boxes are connected by $66 \mathrm{~mm}$ (i.d.) PVC tubing, and can be easily removed or replaced by other structures. The nest whose external dimensions are $33 \times 23 \times 25 \mathrm{~cm}$, was modified after a model designed by Witte (1981). It consists of two sub-units: an upper chamber, representing the nest site filled with hay, connected by zinc coated wire net tunnels ( $1 \mathrm{~mm}$ thick) placed inside PVC tubes, with an underneath chamber (Fig. 2) connecting the nest to the different parts of the accommodation unit. This box has external plywood walls and a removable $20 \mathrm{~mm}$ thick lid. Support, ventilation, prevention from escape, and rapid removal of waste products are guaranteed by a two layer wire net floor, made of $10 \mathrm{~mm}$ and $5 \mathrm{~mm}$ meshes respectively. Direct observation of the moles in the nest is allowed by substituting the plywood lid with a plexiglas one.

The food box and the water box are made of $20 \mathrm{~mm}$ plywood walls having external dimensions of 22 $\times 22 \times 16 \mathrm{~cm}$ resting on a wire net support. Food and water are given through a removable weldmesh cover. An additional wire net layer of $1 \mathrm{~mm}$ meshes is placed between the other two layers with $10 \mathrm{~mm}$ and $5 \mathrm{~mm}$ meshes respectively, to prevent worms escaping.

The activity areas consist of two different structures. The first is a net tunnel made of a zinc coated wire net with $5 \mathrm{~mm}$ meshes with the edges filed and sewed together to produce a run of a diameter of $63 \mathrm{~mm}$. The second is a vertical wooden box with two plexiglas walls and earth inside with external dimensions of $105 \times 90 \times 12 \mathrm{~cm}$. The plexiglas walls coupled with the limited distance between them $(65 \mathrm{~mm})$, have been specifically designed to allow digging and observation of specific behaviours related to digging activities. The total volume of the structure is approximately $44.8 \mathrm{l}$.

We also assembled a horizontal box apt to contain soil, to be used as an alternative to the vertical one. Its external dimensions were $64 \times 40 \times 14 \mathrm{~cm}$, and it was entirely built of $20 \mathrm{~mm}$ plywood, with a removable weldmesh cover with $\mathrm{mm} 10$ meshes. The total volume of the structure was approximately $25.9 \mathrm{l}$.

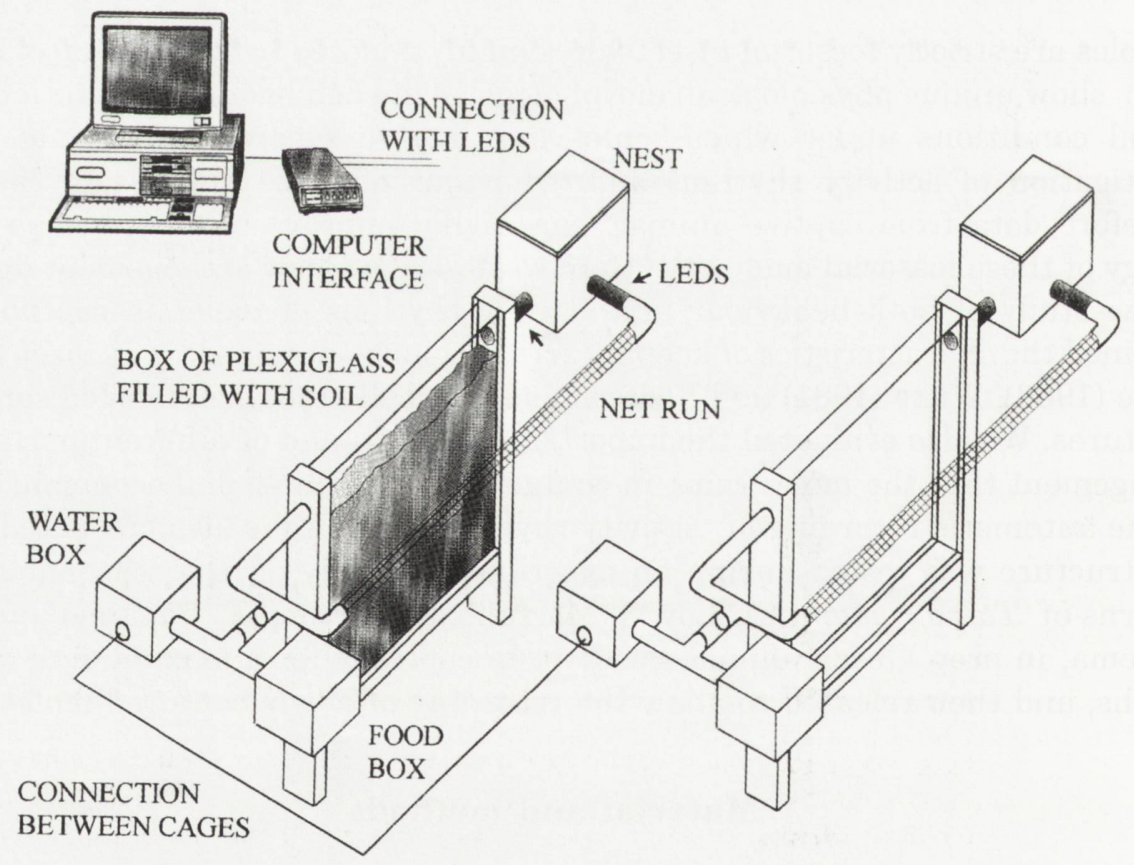

Fig. 1. Schematic representation of the accommodation units. The possible connection between two different units is shown with a line. 


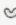

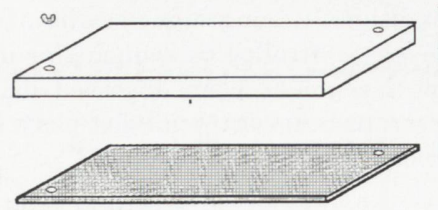

PLYWOOD

REMOVABLE LID

PLEXIGLAS

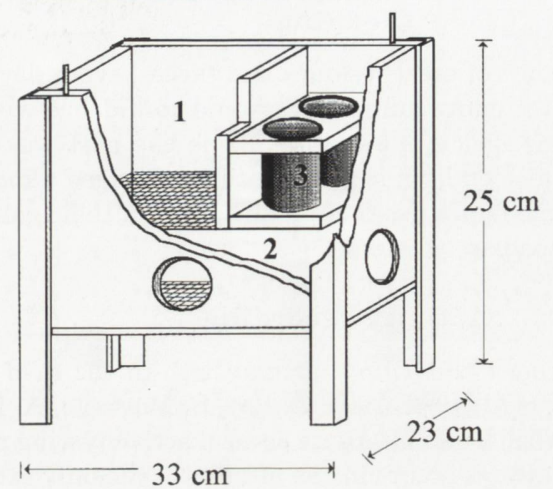

Fig. 2. Details of the nest box: 1. Nest site filled with hay, 2. Underneath chamber, 3. PVC tubes supporting the net tunnels connecting the nest with the underneath chamber.

Connections between cages were possible through net tunnels linking the water boxes. The cages were placed in an outbuilding provided with an air conditioner. Relative humidity was maintained at $90 \%$ to reproduce the natural conditions of mole tunnels that oscillate between $94-100 \%$ (Witte 1981). Animals were exposed to a natural L/D cycle with very dim light entering the room through a window. Artificial light was used only if necessary.

\section{Feeding and handling}

The daily amount of food that should be provided for captive moles survival is still a debated topic. In captive conditions it can vary from $33-50 \%$ to $100 \%$ of their body mass, depending on the kind of food and physiological conditions of the animals (Skoczen 1957, Hawkins and Jewell 1961). In their natural habitat moles feed largely on earthworms, which represent the most important component in their diet throughout the year, followed by other soil invertebrates such as insect larvae, miriapodes and molluscs (Larkin 1948, Godfrey and Crowcroft 1960, Raw 1966, Skoczeń 1966, Funmilayo 1979).

Therefore during the first days of captivity moles were mostly fed on their natural diet, represented by about $50 \mathrm{~g}$ of live earthworms (Eisenia foetida). Chicken liver, heart and kidney (Witte 1981), and tinned dog food (Redfern and Mitchell 1987) were also introduced in the diet from the very first day of captivity and tested for their desirability. The quantity of earthworms was then gradually reduced and the amount of flesh increased. After 3-4 days, moles were maintained permanently on a standard diet consisting of $20 \mathrm{~g}$ of liver, $15 \mathrm{~g}$ of heart and $10 \mathrm{~g}$ of Eisenia foetida. Kidney and tinned dog food were refused, while liver and heart were even preferred to earthworms. Anyway, earthworms and a few insect larvae were always provided to allow the natural assumption of pre-digested fibres and vitamins and to favour the maintenance of intestinal bacterial flora, as recommended by Witte (1981). Earthworms were stored on a Petri dish filled with wet soil to reduce their tendency to escape.

\section{Periodic controls}

Animals were caught at about ten days intervals with a plastic trap positioned in the PVC tube connecting the nest to the vertical box with soil, after occluding with corks the other entries to the 
nest. Moles were then weighted, always before feeding time. Animals were also looked for parasites, examined for health and reproductive conditions. Changes in weight of more or less $15 \mathrm{~g}$ from individual weight at the moment of capture was controlled by reducing or increasing flesh quantity.

In natural conditions the Roman mole has never been observed drinking (Loy et al. 1992). However, water was always available in a Petri dish, for artificial diet has a lower percentage of water than the natural one. Food and water were changed every 24 hours.

\section{Cleaning}

Food and water boxes were cleaned of meal residues and faeces, every day, so as to avoid parasites or fly larvae infestations. In order to reduce animal stress and confidence with the nest box, this was opened and cleaned only if really needed. Anyway, hay inside the nest was never changed but only added. In order to keep good hygienic conditions, soil had to be changed almost totally once a month. This was necessary also because some moles use to drag and store in their galleries pieces of meat, but not earthworms, which are not immediately eaten.

\section{Activity recording}

Previous studies on Talpa europaea and Talpa romana both in the field and in the lab (Godfrey 1955, Gorman and Stone 1990, Loy et al. 1992, 1995, A. Loy, S. Martullo, A. Borroni, E. Capanna and M. P. Gerkema, in prep.), revealed that moles alternate several active/resting periods with a periodicity of about 8 hours. In nature resting always occurs in the nest, with the only exception of some naps of a few minutes occurring out of the nest during activity intervals. This data were confirmed in captivity, ie moles always spent their resting periods inside the nest box. The only exception to this habit was observed during summer, a critical period for the Roman moles. This behaviour allowed to assume that when moles are in the nest for more then 5-6 min they are resting.

Automatic recording of moles' activity was carried out with a computer connected to all the nests. Two pairs of LEDs (a phototransistor BPW 40 and an infrared photodiode TSUSS202C), were placed in each PVC tubing connecting the nest with the rest of the cage (Fig. 1): two pairs between the nest and the net run, and the other two on the tunnel connecting the nest with the vertical structure. The use of two pairs of LEDs for each passage allowed the detection of direction of animal movement from

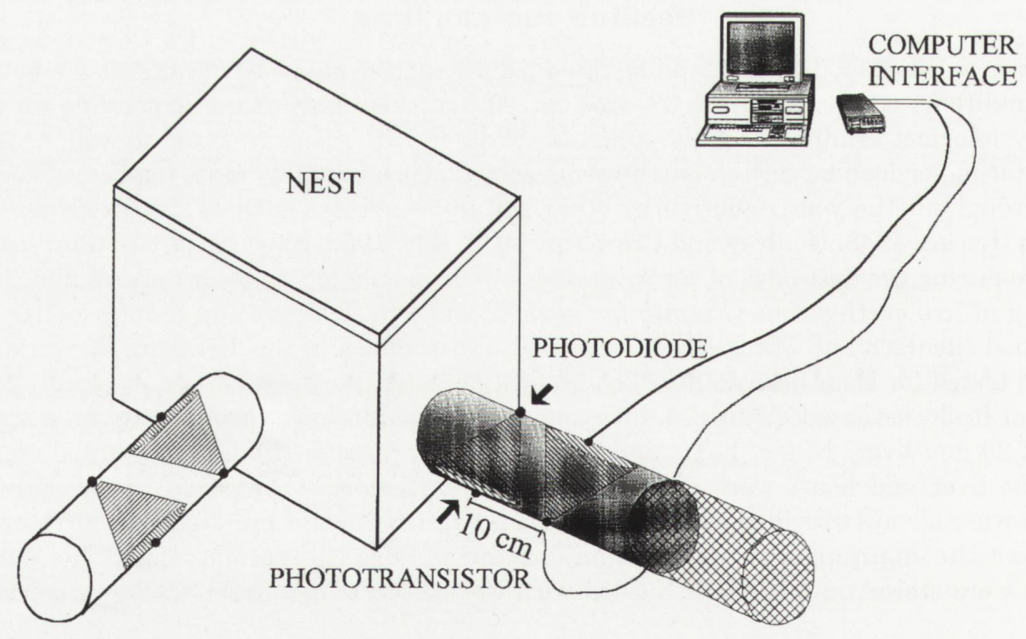

Fig. 3. The system for the automatic recording of activity data. Details for the connection and positioning of the LEDs are shown only for one nest entrance. 
and toward the nest. LEDs were spaced at $10 \mathrm{~cm}$ interval to avoid interference between them. This distance is at least twice as long as the photodiode dispersion semi-cone calculated for the PVC tubing diameter. Eventual interference between the neighbouring pairs of LEDs was avoided by positioning them in an alternate way, with the infrared light cone of a photodiode directed to the photodiode (not to the phototransistor) of the neighbouring couple (Fig. 3). Moreover LEDs were positioned oblique respect to the horizontal section of the tube in order to avoid accumulation of soil, therefore to maintain them sufficiently clean. Anyway is strongly recommended to control and clean LEDs at the beginning of each recording session. LEDs were connected to a computer by means of an interface (a circuit diagram can be sent upon request to the authors). Information from LEDs were filtered through a simple QBASIC program (see Appendix) and stored in the computer as an ASCII file along with date, time and direction of each passage. Data were then transferred to a database for further statistical and graphical analyses. Additional pairs of LEDs can be placed at the entrance of the food box, water box, and soil box, to monitor different kind of activities.

\section{Results and discussion}

The accommodation was tested on four female and four males of Talpa romana, caught between May 1994 and May 1997. Moles were live captured using barrel-like wooden traps and PVC ones placed in actively used tunnels beneath fresh mole hills, checked at 5 hours interval, except during the dry summer season, when intervals were reduced to $3 \mathrm{~h}$ to minimise the stress of captured animals. No bait was placed in the traps. Sex was determined for each animal; reproductive conditions of females (open or close vagina and signs of nursing) were also recorded. Animals were then carried to the lab in a box filled with soil, and then weighted and measured. Moles were kept in the cages for a minimum of 5 to a maximum of 102 days. All the animals survived in captive conditions with optimum health and were afterward released in the field. For the evaluation of health conditions particular attention was devoted to food consumption, since Redfern and Mitchell observed that 1-2 days immediately prior to death moles display a marked fall in food intake and rapidly loose weight (Redfern and Mitchell 1987). Fur was always in good conditions and the two cases of restricted signs of alopecia over the hind feet disappeared after a few days. In two males kept from February to April was observed a curling of the fur in the posterior region of the back. Only one female died after 5 days, but post-mortem examination revealed a state of pregnancy. Since no signs of pathologies were detected, death was imputed to the stress caused by captivity on this particular physiological state.

Data obtained from the periodic weighting of seven animals are visualised in Fig. 4. Body mass of females and males did not vary significantly from the mean $(F$ $=2.17, p=0.128$ for females; $F=0.08, p=0.919$ for males). Mean coefficient of variation for individual moles is $V=5.17$. Highest variations in this coefficient were observed for two animals: in one female $(V=9.12)$, and one male $(V=6.82)$ a decrease of $24 \mathrm{~g}$ and $20 \mathrm{~g}$ respectively were detected at the first control after capture, followed by a relative stabilisation of their weight at successive controls.

The vertical box filled with soil was extensively used by all animals during their active periods, and it was highly preferred to the horizontal one to perform 


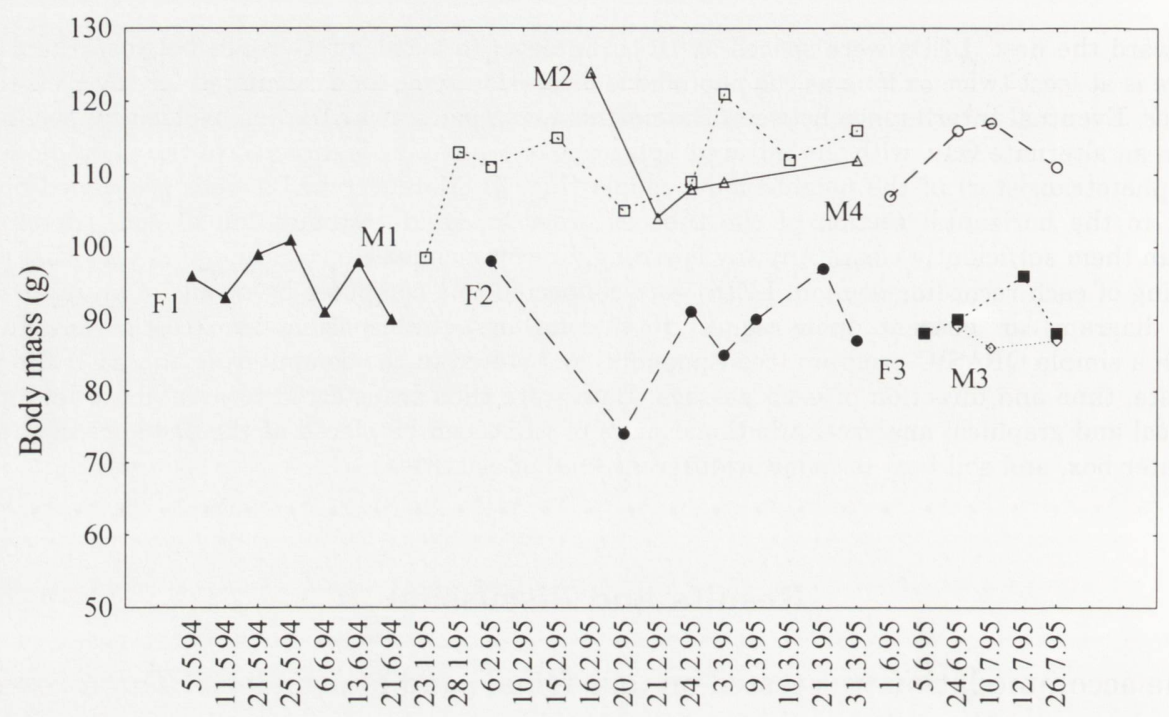

Date

Fig. 4. Body mass variation of seven moles kept in captivity from May 1994 to July 1995. F - female, $\mathrm{M}$ - male.

different kind of activities, like consuming and storing food, escaping from dangers, exploration, digging, etc. For this reason the horizontal cage was removed from the final design of the accommodation unit. Nevertheless the horizontal box, being more easy to handle, can be used as an alternative to the vertical one, when it's necessary to temporarily keep many animals in a small space.

Even if some authors do not agree on the necessity of cages containing soil (Skoczen 1961, Rudge 1966), our observations indicate that availability of soil likely improves moles' welfare and the spectrum of behaviours they can perform. This is in agreement with Godfrey and Crowcroft (1960), Redfern and Mitchell (1987) and Witte (1981), who stressed the importance of soil for captive moles' health.

Finally, even if a low amount of earth (5 l) is sufficient for the survival of the animals if it is given an alternative activity area (Witte 1981), in this case the soil must be cleaned regularly at short intervals (once a week), causing a frequent interference during long-term data recording, as those on activity rhythms.

Moles defecated and urinated in several parts of the accommodation units, creating though distinct huge lavatories inside the nest box, but never in the part of the nest filled with hay. In some cases lavatories were also found in the food box. Lavatories were not found in the vertical box, while defecation and urination were observed at regular length intervals in the net run. Some moles used to drag and bury in their galleries pieces of meat, but not earthworms, which were not immediately eaten, sometimes creating massive deposits.

Our observations confirm that, as many other predatory mammals, moles are opportunistic feeders (Oppermann 1968, Funmilayo 1979, Gorman and Stone 
1990): given the opportunity to choose between liver or heart and their natural food represented by earthworms, they mostly chose the former. This preference was already evident after three-four days of captivity.

Acknowledgements: Special thanks go to Marco De Leonardis for writing the program and constructing the computer interface. We are also indebted to Prof. Luigi Bosco for his practical assistance and precious suggestions during the construction of the unit. The project was supported by the Ministero della Ricerca Scientifica and by the Consiglio Nazionale delle Ricerche, project N. 95.02178.CT04.

\section{References}

Funmilayo O. 1979. Food consumption, preferences and storage in the mole. Acta Theriologica 24: 379-389.

Godfrey G. K. 1955. A field study on the activity of the mole (Talpa europaea). Ecology 36: 678-685.

Godfrey G. K. and Crowcroft P. 1960. The life of the mole (Talpa europaea Linneaus). Museum Press, London: 1-186.

Gorman M. L. and Stone R. D. 1990. The natural history of moles. Christopher Helm Publications, London: 1-138.

Hawkins A. E. and Jewell P. A. 1961. Food consumption and energy requirements of captive British shrews and the mole. Proceedings of the Zoological Society of London 138: 137-155.

Larkin P. 1948. The ecology of mole (T. europaea) populations. Boldleian Library, Oxford: 1-134.

Loy A., Duprè E. and Stone R. D. 1992. Biology of Talpa romana Thomas (Mammalia, Insectivora: Talpidae). 1. Home range and activity patterns: preliminary results derived from a radiotelemetric study. Rendiconti Lincei - Scienze Fisiche e Naturali, serie IX, 3: 173-182.

Loy A., Duprè E. and Capanna E. 1994. Territorial behaviour in Talpa romana, a fossorial insectivore from south-central Italy. Journal of Mammalogy 75: 529-535.

Loy A., Martullo S., Beolchini F. and Capanna E. 1995. Seasonal variation of activity rhythms in the mole Talpa romana (Insectivora, Talpidae). 2nd European Congress of Mammalogy, Abstract Book: 74 .

Oppermann J. 1968. Die nahrung des maulwurfs (Talpa europaea L., 1758) in Unterschiedlichen Lebensraumen. Pedobiologia 8: 59-74.

Redfern R. and Mitchell W. 1987. Successful keeping of European mole (Talpa europaea) in captivity. Journal of Zoology, London 212: 369-373.

Raw F. 1966. The soil fauna as a food source for moles. Journal of Zoology, London 149: 50-54.

Rudge A. J. B. 1966. Catching and keeping live moles. Journal of the Zoological Society, London 149: $42-45$.

Skoczeń S. 1957. A study of the mole (T. europaea L.) in Poland. Part 2. An attempt of keeping moles in captivity. Zeszyty Naukowe Wyższej Szkoły Rolniczej, Kraków, Zootechnika 1(3): 13-34.

Skoczeń S. 1961. A new keeping arrangement for the mole Talpa europaea Linnaeus 1758, in captivity. Acta Theriologica 5: 287-289.

Skoczeń S. 1966. Stomach contents of the mole, Talpa europaea Linnaeus (1758), from southern Poland. Acta Theriologica 11: 551-575.

Witte G. R. 1981. Erfahrungen mit der kafighaltung von maulwurfen (Talpa europaea L.). Zoologische Garten N. F., Jena 51: 193-215.

Received 24 October 1997, revised 26 November 1998, accepted 11 December 1998. 
Appendix. The simple QBASIC program used to decode and store information related to the passages through the LEDs.

10 DIM stato(32)

20 INPUT "name of data file ", nfile\$

30 INPUT "data $\mathrm{dd} / \mathrm{mm} / \mathrm{yy}$ ”, dc $\$$

40 INPUT "hour of the day $\mathrm{hh} / \mathrm{mm} / \mathrm{ss}$ ", oc $\$$

50 TIME $\$=$ "00:00:00"

60 FOR i $=1$ TO 32

70 stato $(\mathrm{i})=0$

80 NEXT i

90 OPEN nfile\$ FOR OUTPUT AS \# 1

100 PRINT \#1, dc\$

105 PRINT \#1, oc\$

110 REM beginning of reading routine

$120 \mathrm{FOR} \mathrm{i}=0$ TO 31

130 OUT \&H378, i + 32

140 lett $=1-(32$ AND INP $(\& H 379)) / 32$

150 IF lett $=0$ AND stato $(\mathrm{i}+1)>1$ THEN GOSUB 1000

$160 \operatorname{stato}(\mathrm{i}+1)=($ lett $+\operatorname{stato}(\mathrm{i}+1)) *$ lett

170 NEXT i

180 tast $\$=$ INKEY\$

190 IF tast $\$=$ "” THEN GOTO 110

200 REM a key has been pushed : end of file

210 CLOSE 1

220 END

1000 REM writing data routine

1005 IF stato $(\mathrm{i}+1)<20$ THEN RETURN

1010 PRINT \# $1, \mathrm{i}+1$

1015 PRINT \#1, TIME\$

1020 PRINT i + 1, TIME\$: RETURN 